\title{
Associations between active commuting, body fat, and body mass index: population based, cross sectional study in the United Kingdom
}

In this Research article by Ellen Flint and colleagues (BMJ 2014;349:g4887, doi:10.1136/bmj.g4887), the caption of table 3 is wrong. It should be: "Results of sex stratified series of linear regression models investigating the association between commuting mode and percentage body fat [not body mass index]."

Cite this as: BMJ 2015;350:h2056

๑ BMJ Publishing Group Ltd 2015 